\title{
Relationships between plasma measures of oxidative stress and metabolic control in NIDDM
}

\author{
J. Nourooz-Z adeh ${ }^{1}$, A . R ahimi ${ }^{2}$, J. Tajaddini-Sarmadi ${ }^{1}$, H . Tritschler ${ }^{3}$, P. R osen ${ }^{4}$, B. H alliwell ${ }^{5}$, D. J. B etteridge ${ }^{1}$ \\ ${ }^{1}$ Department of Medicine, University College Medical School, London, UK \\ ${ }^{2}$ Department of Epidemiology and Public Health, University College, London, UK \\ ${ }^{3}$ ASTA Medica, Frankfurt, Germany \\ ${ }^{4}$ Diabetes-Research Institute, Heinrich-Heine University, Düsseldorf, Germany \\ ${ }^{5}$ International Antioxidant Centre, Pharmacology Group, King's College, London, UK
}

Summary Diabetes mellitus may be associated with increased lipid peroxidation which may contribute to long-term tissue damage. To test this hypothesis, we measured hydroperoxides (ROOHs) as well as $\alpha$-tocopherol in plasma from healthy subjects and individuals with non-insulin-dependent diabetes mellitus (NIDDM) $(n=41$ and 87 , respectively). ROOHs were analysed using the ferrous oxidation with xylenol orange version II (FOX2) assay in conjunction with a specific $\mathrm{ROOH}$ reductant, triphenylphosphine. $\alpha$-Tocopherol was analysed by HPLC with fluorimetric detection. NIDDM patients had lower cholesterol standardised $\alpha$-tocopherol levels as compared to control subjects $(3.3 \pm 1.0$ vs $5.1 \pm 2.3$ $(\mu \mathrm{mol} / \mathrm{l}) /(\mathrm{mmol} / \mathrm{l}) ; \mathrm{p}<0.0005$, Mann-Whitney test): range (1.5-6.5 vs 1.9-13.0, respectively). Plasma ROOHs were substantially higher in the diabetic subjects compared to those of the control subjects (9.4 \pm 3.3 vs $4.1 \pm 2.2 \mu \mathrm{mol} / 1 ; p<0.0005$ Mann-Whitney test: range $2.7-16.8$ vs $0.4-10.3$, respectively). $\mathrm{ROOH} /$ cholesterol standardised $\alpha$-tocopherol ratio was significantly higher in the diabetic patients compared to control subjects (3.2 \pm 1.6 vs $0.9 \pm 0.6$; $p<0.0005$, Mann-Whitney test: range $0.7-8.3$ and $0.1-2.7$, respectively). Plasma levels of ROOHs and $\alpha$-tocopherol were similar in diabetic patients with or without complications as well as in smokers and non-smokers. The present study confirms previous findings from this laboratory that NIDDM is associated with increased oxidative stress as assessed by plasma ROOHs. Increased oxidative stress in diabetic patients appears to be related to the underlying metabolic abnormalities in diabetes, rather than to the complications of this disease. We therefore suggest that oxidative stress is an early stage in the disease pathology, which may contribute to the development of complications. [Diabetologia (1997) 40: 647653]

Keywords NIDDM, lipid hydroperoxides, vitamin E, oxidative stress.
Patients with non-insulin-dependent diabetes mellitus (NIDDM) are at increased risk of developing

Received: 21 October 1996 and in final revised form: 12 February 1997

Corresponding author: Dr. J. Nourooz-Zadeh, Department of Medicine, University College London Medical School, 5 University Street, London WC1E 6JJ, UK

A bbreviations: LDL, Low density lipoproteins; VLDL, very low density lipoproteins; TPP, triphenylphosphine; TBARS, thiobarbituric acid reactive substances; FOX, ferrous oxidation with xylenol orange assay; $\mathrm{ROOH}$, hydroperoxides; NIDDM, non-insulin-dependent diabetes mellitus. vascular and other complications. This excess risk is only partially explained by traditional risk factors including smoking, hypertension and dyslipidaemia [1-3]. Therefore, it has been proposed that oxidative stress is an explanation for accelerated complications in NIDDM [4-7]. A major hypothesis is that low density lipoprotein (LDL) modification by oxidation or glycosylation contributes to tissue damage through cytotoxic reactions with endothelial cells or through further reactions to generate 'modified' LDL which is selectively accummulated by 'scavenger' receptors [8].

Consistent with this view, it has been shown that diabetic patients have larger amounts of dense LDL 
as compared to control subjects. Dense LDL is more readily oxidised than more buoyant LDL [9]. LDL from diabetic patients also has higher levels of advanced glycation end products as compared to control subjects [10]. Freshly isolated very low density lipoprotein (VLDL) and LDL from diabetic rats is more oxidisable, as well as more cytotoxic to fibroblast cells, than those from non-diabetic rats [11]. It has also been shown that the extent of lipoprotein peroxidation and toxicity is inhibited by treatment of the rats with probucol or vitamin $\mathrm{E}$ ( $\alpha$-tocopherol) [11]. Depletion of serum and cellular antioxidants including $\alpha$-tocopherol, ascorbate and thiols also occurs in NIDDM patients, consistent with enhanced consumption due to oxidation [12].

Despite the biochemical importance of oxidative stress its measurement in vivo has been difficult [13]. This problem has been approached in two ways: 1) measurement of reaction products of oxidative damage such as lipid peroxides; and 2) measurement of the depletion of antioxidants. Enhanced lipid peroxidation in diabetic patients has been reported using thiobarbituric acid reactive substances (TBARS) as an assay [14-18]. However, interpretation of the relationship between lipid peroxidation and diabetes has yielded contradictory results $[14,15,18,19]$. The simple TBARS assay measures many parameters in addition to lipid peroxidation and is affected by the lipid content of the sample [20]. Thus, it is unclear to what extent plasma lipoprotein peroxidation assessed by this method accounts for biological changes associated with oxidative stress. Data are also conflicting regarding $\alpha$-tocopherol status in diabetic subjects. Some studies report no changes, others a decrease and yet others an increase [21-23]. One problem in such studies is that failure to lipid-standardise $\alpha$-tocopherol can give misleading results in hyperlipidaemic patients. Recently, we used the ferrous oxidation with xylenol orange (FOX) assay, coupled with the selective hydroperoxide reductant triphenylphosphine (TPP), to determine levels of lipid hydroperoxides (ROOH) in NIDDM [24]. For 22 individuals with NIDDM, a mean level of $9.04 \pm 4.3 \mu \mathrm{mol} / \mathrm{l}$ was recorded. This level was higher $(p<0.0005$; separate variance test) than plasma $\mathrm{ROOH}$ from control subjects $(3.76 \pm 2.48 \mu \mathrm{mol} / \mathrm{l})$. There was no difference between levels of plasma malondialdehyde using the TBA-test between NIDDM or control subjects $(1.00 \pm 0.70$ vs $1.21 \pm 0.62 \mu \mathrm{mol} / 1 ; p<0.1)$.

The current study was undertaken to assess plasma lipid hydroperoxides and $\alpha$-tocopherol concentration in larger groups of NIDDM and healthy control subjects ( 87 and 41 individuals, respectively) and have attempted to relate these parameters to the presence of complications.

We also propose that $\mathrm{ROOH} /$ cholesterol standardised $\alpha$-tocopherol ratio is a clinically more relevant measure of oxidative stress in diabetes.

\section{Subjects, materials and methods}

Subject recruitment and characterization. We recruited 87 NIDDM subjects from well-characterized patients attending the University College London Hospitals' Diabetic Service. Patients were assessed for the presence of diabetic complications with particular reference to large vessel disease. History of myocardial infarction substantiated by ECG and enzyme changes was noted. Presence of angina was confirmed by exercise ECG and exercise thallium test. Retinopathy was determined by direct ophthalmoscopy through a dilated pupil. Peripheral neuropathy was assessed clinically using the scoring system described by Volk et al. [25] which provides a reasonable and quantifiable estimate of nerve function measured neurophysiologically. Urinary albumin excretion rate (AER: $\mu \mathrm{g} / \mathrm{min}$ ) was measured by an enzyme linked immunoassay and calculated as the mean of three timed overnight urine collections [26]. To allow unequivocal group separation normoalbuminuria was defined as below $10 \mu \mathrm{g} / \mathrm{min}$, microalbuminuria as $30-200 \mu \mathrm{g} / \mathrm{min}$ and macroproteinuria as above $250 \mu \mathrm{g} / \mathrm{min}$. Patients were subdivided into two groups withand without evidence of complications $(n=49$ and 38, respectively). Primary complications include retinopathy, neuropathy, nephropathy, chronic heart disease and stroke $(n=26,6$, $8,5,3$ and 1 , respectively). Non-smokers $(n=61)$ were defined as those individuals who had never smoked or claimed to have stopped smoking at least 3 years prior to plasma sampling for the study. Diabetic subjects were treated by diet alone or by diet plus oral hypoglycaemic agents (metformin and/or tolbutamide). Healthy volunteers $(n=41)$ were recruited from the Rayne Institute, UCL, Medical School. None of the control subjects was a smoker, on any special diet, taking vitamin E or any medication related to atherosclerosis or diabetes before taking part in this study. This study was approved by the joint UCL/UCH ethical committee of the UCL, Medical School.

Reagents. Ammonium ferrous sulphate, hydrogen peroxide $\left(\mathrm{H}_{2} \mathrm{O}_{2}\right)$ and butylated hydroxytoluene were obtained from Sigma Chemical Company (Poole, Dorset, UK). Xylenol orange [o-cresolsulphonphthalein-3, 3-bis(methyliminodiacetic acid sodium salt)] and TPP were purchased from Aldrich (Gillingham, Dorset, UK).

Preparation of plasma. Blood was collected by venipuncture into sampling vials $(10 \mathrm{ml})$ containing heparin. Plasma was obtained by centrifugation at $2000 \mathrm{~g}$ for $10 \mathrm{~min}$ at room temperature. For the ROOH assay, plasma was kept on ice and was analysed within $3 \mathrm{~h}$.

Clinical laboratory measurements. Fasting plasma glucose was measured by using a glucose oxidase method. Glycated haemoglobin $\mathrm{A} 1\left(\mathrm{Hb}_{\mathrm{A} 1}\right)$ was measured by agarose gel electrophoresis [27]. Total plasma cholesterol was measured using the Cholesterol-C high performance CHOD-PAP method (Boehringer Mannheim GmbH; Diagnostics and Biochemicals, East Sussex, UK). Total triglyceride was measured using the GPO-PAP high-performance enzymatic colorimetric test (Boehringer Mannheim $\mathrm{GmbH}$ ).

\section{M easurement of indices of lipid peroxidation}

Hydroperoxides. Whole plasma ROOHs were determined using the ferrous oxidation in xylenol orange, Version II (FOX assay for lipid ROOHs) [24, 28]. Briefly, 90- $\mu$ l aliquots of plasma were transferred into $6(1.5 \mathrm{ml})$ microcentrifuge vials; $10 \mu \mathrm{l}$ 
of $10 \mathrm{mmol} / \mathrm{l} \mathrm{TPP}$ in methanol was added to 3 vials to remove ROOHs; $10 \mu$ of methanol was added to the remaining 3 vials. This generated blank and test samples, respectively. All vials were then vortexed and incubated at room temperature for 30 min prior to the addition of $900 \mu \mathrm{l}$ FOX 2 reagent with mixing. After incubation at room temperature for a further $30 \mathrm{~min}$, the vials were centrifuged at $12000 \mathrm{~g}$ at $25^{\circ} \mathrm{C}$ for $10 \mathrm{~min}$. Absorbance of the supernatant was then determined at $560 \mathrm{~nm}$. ROOH content in the plasma samples was determined as a function of the mean absorbance difference of samples with and without elimination of ROOH by TPP. The standard deviation was taken as the larger of the standard deviations of the measurements obtained with or without TPP treatment.

$\alpha$-Tocopherol analysis. Plasma samples $(200 \mu \mathrm{l})$ were mixed with $500 \mu \mathrm{l}$ ethanol (containing $50 \mathrm{ng} / \mathrm{ml}$ of $\gamma$-tocopherol as internal standard), total lipids were partitioned with hexane $(500 \mu \mathrm{l})$ and the solvent was subsequently dried under a stream of nitrogen. The residue was then redissolved in $200 \mu \mathrm{l}$ acetonitrile. HPLC separation was performed on a Hypersil-ODS column $(10 \mathrm{~cm} \times 5 \mathrm{~mm}$, particle size $5 \mu \mathrm{m}$; Chrompack, Middelburg, the Netherlands). Tocopherols were monitored fluorometrically (emission: $295 \mathrm{~nm}$; Excitation: $340 \mathrm{~nm}$ ) [24]. We decided to cholesterol standardise plasma $\alpha$-tocopherol levels because: a) $\alpha$-tocopherol is mainly transported by cholesterol; b) cholesterol levels are less subject to diurnal variation than total lipids [29].

Statistical analysis was performed using the Unistat Desktop Statistical Analysis package version 3 (Unistat Ltd, London, UK) and NCSS Version 6.0 (Number Cruncher Statistical Systems, Kaysville, Utah, USA). Data are expressed as mean \pm SD. The results are expressed as mean with $95 \%$ confidence intervals since data are skewed. A non-parametric test was used to evaluate the difference in plasma biochemical parameters in healthy and diabetic subjects. P-values less than 0.05 (two-tailed) were considered significant.

\section{Results}

Table 1 shows the clinical characteristics of the patients and control subjects as well as the differences in levels of plasma ROOHs, $\alpha$-tocopherol, cholesterol standardised $\alpha$-tocopherol and ROOHs/cholesterol standardised $\alpha$-tocopherol. The NIDDM individuals had elevated fasting blood glucose, $\mathrm{HbA}_{1}$, triglycerides and cholesterol levels compared to the control subjects. Mean age of the diabetic patients was significantly higher compared to that of the control subjects [58.4 \pm 14.7 vs $38.2 \pm 12.3 ; p<0.0005]$. Since plasma ROOH levels in neither diabetic nor control subjects was explained by age [24] we did not age-standardise patients and control subjects. The data spread for plasma ROOHs in control and the diabetic subjects is shown in Figure 1. The coefficient of variation for individual plasma samples using this method is typically less than $5 \%$ which is in agreement with a previous study [24].

Absolute plasma $\alpha$-tocopherol levels in the diabetic subjects were slightly, but significantly, lower than those of the control subjects $[19.6 \pm 3.3$ vs
Table 1. Clinical characteristics of healthy and NIDDM individuals

\begin{tabular}{|c|c|c|c|}
\hline Variables & Healthy & NIDDM & $P$ value \\
\hline$n$ & 41 & 87 & - \\
\hline Sex (female/male) & $24 / 17$ & $40 / 47$ & - \\
\hline Age (years) & $\begin{array}{l}38.2 \pm 12.3 \\
{[21-69]}\end{array}$ & $\begin{array}{l}58.4 \pm 14.7 \\
{[17-86]}\end{array}$ & $<0.0005$ \\
\hline Diabetes duration (years) & - & $\begin{array}{l}12.0 \pm 8.3 \\
{[0.0-44]}\end{array}$ & - \\
\hline Total cholesterol (mmol/l) & $\begin{array}{l}5.0 \pm 1.1 \\
{[1.4-6.9]}\end{array}$ & $\begin{array}{l}6.0 \pm 1.3 \\
{[3.3-9.9]}\end{array}$ & $<0.002$ \\
\hline Triglycerides (mmol/l) & $\begin{array}{l}0.9 \pm 0.5 \\
{[0.3-2.5]}\end{array}$ & $\begin{array}{l}2.8 \pm 1.8 \\
{[0.6-3.5]}\end{array}$ & $<0.0005$ \\
\hline Fasting glucose $(\mathrm{mmol} / \mathrm{l})$ & $\begin{array}{l}4.9 \pm 0.4 \\
{[4.2-5.8]}\end{array}$ & $\begin{array}{l}12.1 \pm 5.1 \\
{[1.9-28.9]}\end{array}$ & $<0.0005$ \\
\hline $\mathrm{HbA}_{1}(\%)$ & $\frac{-}{(5-8)^{b}}$ & $\begin{array}{l}11.0 \pm 2.4 \\
{[5.9-17.8]}\end{array}$ & - \\
\hline $\mathrm{ROOH}(\mu \mathrm{mol} / \mathrm{l})$ & $\begin{array}{l}4.1 \pm 2.2 \\
{[0.4-10.3]}\end{array}$ & $\begin{array}{l}9.4 \pm 3.3 \\
{[2.7-16.8]}\end{array}$ & $<0.0005$ \\
\hline$\alpha$-Tocopherol $(\mu \mathrm{mol} / \mathrm{l})$ & $\begin{array}{l}23.8 \pm 8.3 \\
{[10.6-47.0]}\end{array}$ & $\begin{array}{l}19.6 \pm 7.5 \\
{[8.6-44.3]}\end{array}$ & $<0.05$ \\
\hline $\begin{array}{l}\alpha \text {-Tocopherol/cholesterol } \\
(\mu \mathrm{mol} / \mathrm{l}) /(\mathrm{mmol} / \mathrm{l})\end{array}$ & $\begin{array}{l}5.1 \pm 2.3 \\
{[1.9-13.0]}\end{array}$ & $\begin{array}{l}3.3 \pm 1.0 \\
{[1.5-6.2]}\end{array}$ & $<0.0005$ \\
\hline $\begin{array}{l}\mathrm{ROOH} /(\alpha \text {-tocopherol/ } \\
\text { cholesterol })\end{array}$ & $\begin{array}{l}0.9 \pm 0.6 \\
{[0.1-2.7]}\end{array}$ & $\begin{array}{l}3.2 \pm 1.6 \\
{[0.7-8.3]}\end{array}$ & $<0.0005$ \\
\hline
\end{tabular}

Data are mean \pm SD and [range] or (normal range)

$23.8 \pm 8.3 \mu \mathrm{mol} / 1 ; p<0.05]$. On the other hand, plasma $\alpha$-tocopherol levels between the two groups differed markedly when $\alpha$-tocopherol levels were expressed per unit cholesterol $3.3 \pm 1.0$ vs $5.1 \pm 2.3$ $(\mu \mathrm{mol} / \mathrm{l}) /(\mathrm{mmol} / \mathrm{l})[\mathrm{p}<0.0005]$. Cholesterol standardised $\alpha$-tocopherol levels in female diabetic patients and control subjects were $3.3 \pm 1.0$ vs $5.3 \pm 2.6(\mu \mathrm{mol} / \mathrm{l}) /$ $(\mathrm{mmol} / \mathrm{l})[\mathrm{p}<0.0005]$. The corresponding levels in male subjects were $3.3 \pm 0.9$ vs $4.3 \pm 1.3(\mu \mathrm{mol} / \mathrm{l}) /$ $(\mathrm{mmol} / \mathrm{l}) ;[\mathrm{p}<0.005]$. There was no correlation between age and absolute- or cholesterol standardised plasma $\alpha$-tocopherol concentration and in diabeticor control subjects. The mean level of plasma ROOH was significantly higher in the NIDDM subjects compared to control subjects $[9.4 \pm 3.3$ vs $4.1 \pm 2.2 \mu \mathrm{mol} / 1]$. There was no correlation between age and ROOHs in either patient or control groups (Pearson's $r=-0.2$ and $-0.1 ; p<0.5$ ). Furthermore, ROOHs in diabetic or control subjects did not correlate with total cholesterol, triglyceride, $\alpha$-tocopherol or $\mathrm{HbA}_{1}$, consistent with previous findings [24]. $\mathrm{ROOH}$ concentrations in female diabetic and control subjects were $(9.9 \pm 3.2$ vs $4.9 \pm 2.3 \mu \mathrm{mol} / \mathrm{l}$; $\mathrm{p}<0.0005)$. The corresponding levels for males were $9.1 \pm 3.3$ vs $3.0 \pm 1.6 \mu \mathrm{mol} / 1 ; p<0.0005)$.

Expression of plasma $\mathrm{ROOH}$ levels per unit of cholesterol standardised $\alpha$-tocopherol also revealed that $\mathrm{ROOH} /$ cholesterol standardised $\alpha$-tocopherol ratio in the NIDDM subjects was significantly elevated compared to that of the control subjects 

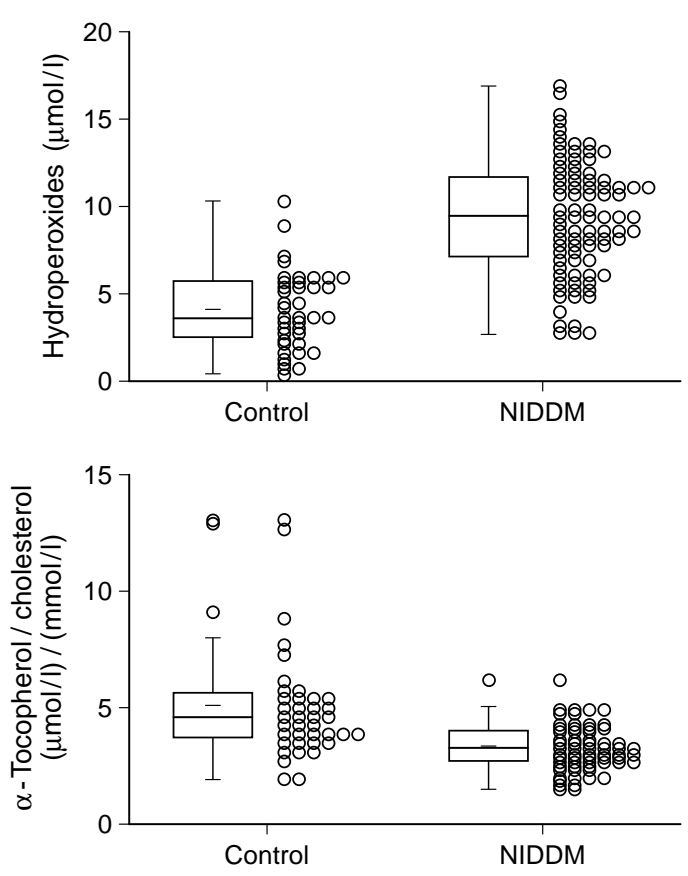

Fig. 1. Data spread for ROOHs (upper) and cholesterol standardised $\alpha$-tocopherol (lower) in control and NIDDM subjects

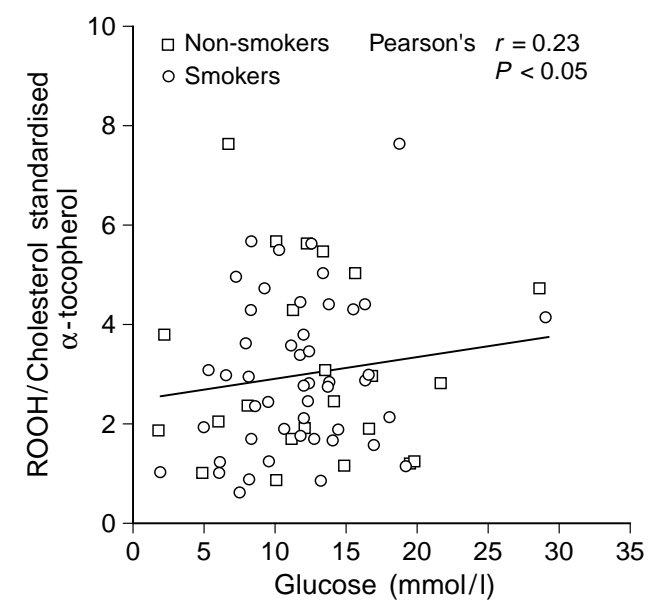

Fig. 2. Correlation between $\mathrm{ROOH} /$ cholesterol standardised ratio and fasting blood glucose levels in NIDDM subjects

$(3.2 \pm 1.6$ vs $0.9 \pm 0.6) . \mathrm{ROOH} /$ cholesterol standardised $\alpha$-tocopherol ratio did not correlate with age, cholesterol, triglycerides or $\mathrm{HbA}_{1}$ in diabetic or control subjects. There was, however, a relation between $\mathrm{ROOH} /$ cholesterol standardised $\alpha$-tocopherol ratio and fasting blood glucose (Pearson's $r=0.23$; $p<0.05$ ) in the diabetic patients only (Fig. 2).

Absolute- and cholesterol standardised plasma $\alpha$ tocopherol, $\mathrm{ROOH}$ and $\mathrm{ROOH} /$ cholesterol standardised $\alpha$-tocopherol ratio levels were very similar in patients with complications (including retinopathy, neuropathy, nephrophy or vascular) and without complications. Furthermore, there was no difference in absolute- and cholesterol standardised $\alpha$-tocopherol, ROOHs or ROOH/cholesterol standardised $\alpha$-tocopherol ratio between diabetic patients with retinopathy compared to those without the complication. The above parameters were not evaluated for individual complications as the numbers were too small. Table 2 summarises the clinical characteristics of diabetic subjects with and without complications.

Among the diabetic patients, plasma absolute- and cholesterol standardised $\alpha$-tocopherol concentrations were very similar in smokers and non-smokers. On the other hand, ROOHs as well as ROOH/cholesterol $\alpha$-tocopherol standardised ratios were slightly higher in non-smokers than in smokers. Table 3 gives the clinical characteristics of smokers and non-smokers.

\section{Discussion}

Oxidative stress has been proposed as a major component in the events that cause late complications in patients with diabetes mellitus. A prerequisite for animal experimental models and studies in human diabetes is sensitive and reliable laboratory tools for detecting oxidative stress. In the present cross-sectional study of well-characterised individuals with NIDDM, plasma total ROOHs were specifically measured using the FOX2-assay with TPP authentication of the signal [24, 28].

Plasma hydroperoxide assays are divided into two catagories including total- and individual hydroperoxide classes. Individual hyroperoxide classes are measured by HPLC-linked microperoxidase -derived isoluminol chemiluminescence (CL) techniques while total values are assayed using colourometric-, chemiluminescence- or enzymatic techniques. Total plasma hydroperoxides have been estimated to be between 0.5 and $5.5 \mu \mathrm{mol} / 1$ using different techniques [30-34]. Using HPLC-CL assays, plasma levels of phospholipid hydroperoxides have been reported to range from 10 to $500 \mathrm{nmol} / 1$ [35-37]. Cholesteryl ester hydroperoxide levels are reported to be as low as 3 $\mathrm{nmol} / \mathrm{l}[38,39]$ or as high as $920 \mathrm{nmol} / \mathrm{l}[40]$.

Some investigators have reported an association between TBARS and diabetic complications $[16,18]$ while other have not [14]. Jennings et al. [41] reported that elevated levels of conjugated dienes in plasma from diabetic subjects are associated with microangiopathy. MacRury et al. [15] compared different methods (conjugated dienes, TBARS and chemiluminescence) of assessing free radical activities in diabetic subjects. In each case, diabetes was associated with elevated levels of different indirect measurement of lipid peroxidation. However, they did not show any relationship between diabetic complications and plasma measures of oxidative stress. More recently, elevated levels of plasma 8-epi $\mathrm{PGF}_{2} \alpha$, a 
Table 2. Clinical characterisation of NIDDM subjects with and without complications

\begin{tabular}{|c|c|c|c|}
\hline Variables & $\begin{array}{l}\text { No compli- } \\
\text { cations }\end{array}$ & $\begin{array}{l}\text { Compli- } \\
\text { cations }\end{array}$ & $P$ value \\
\hline $\mathrm{n}$ & 38 & 49 & - \\
\hline Age (years) & $\begin{array}{l}53.3 \pm 13.7 \\
{[17-82]}\end{array}$ & $\begin{array}{l}62.3 \pm 14.1 \\
{[31-86]}\end{array}$ & $<0.005$ \\
\hline Total cholesterol $(\mathrm{mmol} / \mathrm{l})$ & $\begin{array}{l}5.6 \pm 1.2 \\
{[3.3-9.9]}\end{array}$ & $\begin{array}{l}6.4 \pm 1.1 \\
{[4.2-9.9]}\end{array}$ & $<0.05$ \\
\hline Triglycerides (mmol/l) & $\begin{array}{l}2.5 \pm 1.5 \\
{[0.7-6.2]}\end{array}$ & $\begin{array}{l}3.1 \pm 1.9 \\
{[0.5-9.5]}\end{array}$ & NS \\
\hline Fasting glucose $(\mathrm{mmol} / \mathrm{l})$ & $\begin{array}{l}11.4 \pm 5.4 \\
{[1.9-28.9]}\end{array}$ & $\begin{array}{l}12.7 \pm 5.1 \\
{[2.3-28.5]}\end{array}$ & NS \\
\hline $\mathrm{HbA}_{1}(\%)$ & $\begin{array}{l}10.9 \pm 2.5 \\
{[5.9-16.8]}\end{array}$ & $\begin{array}{l}11.1 \pm 2.3 \\
{[6.9-17.8]}\end{array}$ & NS \\
\hline $\mathrm{ROOH}(\mu \mathrm{mol} / \mathrm{l})$ & $\begin{array}{l}9.5 \pm 3.3 \\
{[2.7-15.5]}\end{array}$ & $\begin{array}{l}9.4 \pm 3.4 \\
{[2.7-16.8]}\end{array}$ & NS \\
\hline$\alpha$-Tocopherol $(\mu \mathrm{mol} / \mathrm{l})$ & $\begin{array}{l}18.6 \pm 5.6 \\
{[9.2-30.9]}\end{array}$ & $\begin{array}{l}20.4 \pm 8.7 \\
{[8.6-44.3]}\end{array}$ & NS \\
\hline $\begin{array}{l}\alpha \text {-Tocopherol/cholesterol } \\
(\mu \mathrm{mol} / \mathrm{l}) /(\mathrm{mmol} / \mathrm{l})\end{array}$ & $\begin{array}{l}3.4 \pm 0.9 \\
{[1.9-5.0]}\end{array}$ & $\begin{array}{l}3.2 \pm 1.0 \\
{[1.5-6.2]}\end{array}$ & NS \\
\hline $\begin{array}{l}\mathrm{ROOH} /(\alpha \text {-tocopherol/ } \\
\text { cholesterol })\end{array}$ & $\begin{array}{l}3.0 \pm 1.4 \\
{[0.6-6.1]}\end{array}$ & $\begin{array}{l}3.3 \pm 1.6 \\
{[0.9-8.3]}\end{array}$ & NS \\
\hline
\end{tabular}

Data are mean \pm SD and [range]

NS, Not significant

Table 3. Clinical characteristics of NIDDM subjects in relation to smoking habits

\begin{tabular}{llll}
\hline Variables & Non-smokers & Smokers & P value \\
\hline $\mathrm{n}$ & 61 & 26 & - \\
Age (years) & $60.0 \pm 14.2$ & $54.5 \pm 15$ & $\mathrm{NS}$ \\
& {$[17-86]$} & {$[21-80]$} & \\
Total cholesterol $(\mathrm{mmol} / \mathrm{l})$ & $6.0 \pm 1.2$ & $6.1 \pm 1.4$ & $\mathrm{NS}$ \\
& {$[3.3-9.4]$} & {$[4.4-9.9]$} & \\
Triglycerides $(\mathrm{mmol} / \mathrm{l})$ & $2.6 \pm 1.4$ & $3.2 \pm 2.4$ & $\mathrm{NS}$ \\
& {$[0.7-6.2]$} & {$[0.5-9.5]$} & \\
Fasting glucose $(\mathrm{mmol} / \mathrm{l})$ & $11.8 \pm 4.8$ & $12.9 \pm 6.2$ & $\mathrm{NS}$ \\
& {$[2-28.9]$} & {$[1.9-28.5]$} & \\
HbA $1 \%)$ & $10.8 \pm 2.2$ & $11.6 \pm 2.6$ & $\mathrm{NS}$ \\
& {$[6.9-16.8]$} & {$[5.9-17.8]$} & \\
$\mathrm{ROOH}(\mu \mathrm{mol} / \mathrm{l})$ & $9.6 \pm 3.2$ & $9.0 \pm 3.3$ & $\mathrm{NS}$ \\
& {$[2.7-16.8]$} & {$[2.7-14.6]$} & \\
$\alpha-$ Tocopherol $(\mu \mathrm{mol} / \mathrm{l})$ & $19.2 \pm 7.4$ & $20.4 \pm 7.8$ & $\mathrm{NS}$ \\
& {$[8.6-42.3]$} & {$[10.0-44.3]$} & \\
$\alpha-$ Tocopherol/cholesterol & $3.2 \pm 0.9$ & $3.4 \pm 1.0$ & $\mathrm{NS}$ \\
$(\mu \mathrm{mol} / \mathrm{l}) /(\mathrm{mmol} / \mathrm{l})$ & {$[1.5-5.0]$} & {$[1.7-6.2]$} & \\
$\mathrm{ROOH} /(\alpha-$ tocopherol/ & $3.4 \pm 1.6$ & $2.7 \pm 1.3$ & $<0.1$ \\
cholesterol $)$ & {$[1.1-8.3]$} & {$[0.7-5.9]$} & \\
\hline
\end{tabular}

Data are mean \pm SD and [range]

specific non-enzymatic peroxidation product derived from arachidonic acid, has been reported; association between 8-epi $\mathrm{PGF}_{2} \alpha$ and diabetic complications was not discussed [42]. In this study, diabetic patients had 2.3 times higher plasma lipid ROOH levels as compared to control subjects confirming previous data from our laboratory [24]. The elevated level of plasma ROOHs in the diabetic subjects was not influenced by sex, age, smoking habit or diabetic complications. Our data suggest that the elevated levels of plasma $\mathrm{ROOH}$ in patients are associated with the diabetes itself.

A number of studies have reported absolute or lipid standardised vitamin E concentrations in plasma from diabetic patients. Tsai et al. [22] reported no changes in absolute $\alpha$-tocopherol levels whereas others have reported decreases and even increases [23, $43,44]$. In this study, diabetic patients had significantly lower levels of $\alpha$-tocopherol compared to control subjects. $\alpha$-Tocopherol concentrations in the diabetic patients were still low even when the levels were expressed per unit cholesterol. These findings are similar to results of other investigators studying antioxidant vitamins in relation to risk factors in diabetic subjects $[18,45]$. The sex of diabetic or control subjects had no significant influence on $\alpha$-tocopherol levels. Variation in age did not explain the lower levels of plasma $\alpha$-tocopherol in this population of diabetic subjects since there was no correlation between age and $\alpha$-tocopherol content in NIDDM or control subjects. The change in cholesterol standardised $\alpha$-tocopherol was very similar in our diabetic subjects with and without complications as well as in smokers and non-smokers. These data together suggest that the low plasma $\alpha$-tocopherol status in diabetes is associated with the syndrome itself. Another factor responsible for the above abnormality in the diabetic subjects could be chronic low dietary intake of antioxidants. More research into this area is required to clarify these points.

It has been shown that whole plasma and isolated LDL from NIDDM patients are more prone to peroxidation as compared to that of control subjects; and that vitamin $\mathrm{E}$ supplementation decreased peroxidation of whole plasma as well as isolated lipoprotein fractions [46-48]. Diabetic platelets are postulated to be deficient in $\alpha$-tocopherol and their dysfunction is partially normalised by $\alpha$-tocopherol therapy [49]. Salonen et al. [50] suggested that low $\alpha$-tocopherol is a risk factor for onset of NIDDM. High intake of vitamin $\mathrm{E}$ has been shown to be associated with a lower risk of coronary heart disease in human studies [51-53]. Thus, the decline in $\alpha$-tocopherol levels in diabetic subjects may reflect part of a continuous cycle of oxidative stress and damge induced by the syndrome.

Another important point from our data is that plasma from diabetic patients had substantially higher $\mathrm{ROOH}$ content as compared to control subjects when the levels were expressed per unit cholesterol standardised $\alpha$-tocopherol. The $\mathrm{ROOH} /$ cholesterol standardised $\alpha$-tocopherol ratio in the diabetic patients was 3.6 times higher as compared to the control subjects; the difference in $\mathrm{ROOH}$ levels alone was 2.3 fold. The $\mathrm{ROOH} /$ cholesterol standardised 
$\alpha$-tocopherol ratio also showed a scatter pattern but a significant association with fasting blood glucose only in the patient group; $\mathrm{ROOH}$ values alone did not show a relationship. We were concerned that the relationship between $\mathrm{ROOH} /$ cholesterol standardised $\alpha$ tocopherol ratio in the diabetic patients was in fact a deterioration due to the cigarette smoking rather than fasting blood glucose. Interestingly, a strong association between $\mathrm{ROOH} /$ cholesterol standardised ratio and fasting blood glucose levels was found in non-smoking diabetic patients (Pearson's $r=0.36$; $p<0.01$ ); smokers did not show a relationship (Pearson's $r=0.06 ; p<0.4)$. These findings suggest that brittleness of diabetes may determine plasma hydroperoxide concentrations. This would also be consistent with the hypothesis that unstable glycaemia rather than chronic hyperglycaemia is a major risk factor in the long-term complications of NIDDM. Therefore, we propose that this marker is a better index of oxidative stress/antioxidant status than ROOHs or $\alpha$-tocopherol alone since any changes in plasma lipid peroxidation will be dependent on the degree of saturation of plasma lipids by $\alpha$-tocopherol. This marker should be a useful tool in trials examining antioxidant prevention of diabetic complications and the impact of various therapeutic interventions.

In summary, we have shown that NIDDM is associated with increased ROOHs and low $\alpha$-tocopherol which appears to be unrelated to abnormalities in lipid metabolism. An important point from our data is that $\mathrm{ROOH}$ levels are high even in diabetic patients without complications. We therefore suggest that oxidative stress is an early stage in the disease pathology. It pre-dates the complications, it is not simply a consequence of the complications.

A cknowledgements. We are grateful to the British Heart Foundation for financial support.

\section{References}

1. Pyorala K,Laakso M, Uusitupa M (1987) Diabetes and atherosclerosis:an epidemiological view. Daibetes 3: 463-524

2. Kanell WB, Hjorland M, Castelli WP (1974) Role of diabetes in cardiac disease:conclusion from population studies. Am J Cardiol 34: 29-34

3. Uusittupa M, Niskanen LK, Siitonen O, Voutilainen E, Pyorala K(1990) Five-years incidence of atherosclerotic vascular disease in relation to general risk factors, insulin level, and abnormalities in lipoprotein composition in NIDDM and non-diabetic subjects. Circulation 82: 27-36

4. Oberley LW(1988) Free radicals and diabetes. Free Radical Biol Med. 5: 113-124

5. Baynes JW (1991) Perspectives in diabetes: role of oxidative stress in development of complications in diabetes. Diabetes 40: 405-412

6. Wolff SP (1993) Diabetes and free radicals. In: Cheeseman KH, Slater TF (eds) Free radicals in medicine. British Medical Bulletin, Vol 49. Churchill Livingstone
Edinburgh London Madrid Mellbourne New York Tokyo, pp 642-652

7. Giugliano D, Ceriello A, Paolisso G (1995) Diabetes mellitus, hypertension, and cardiovascular disease: which role for oxidative stress? Metabolism 44: 363-368

8. Steinberg D, Parthasarathy S, Carew TE, Khoo JC, Witztum JL (1989) Beyond cholesterol: modification of LDL that increase atherogenicity. New Engl J Med 320: 915-924

9. Feingold KR, Grunfeld C, Pang M, Doerrler M, Krauss RM (1992) LDL subclass pheotypes and triglyceride metabolism in NIDDM. Arterioscler Throm 12: 1496-1502

10. Sobenin LA, Tertov VV, Koschinsky T et al. (1993) Modified LDL from diabetic patients causes cholesterol accumulation in human aortic cells. Atherosclerosis. 100: 41-54

11. Morel DW, Chisolm GM (1989) Antioxidant treatment of diabetic rats inhibits lipoprotein oxidation and cytotoxicity. J Lipid Res 30: 1827-1834

12. Lyons TJ (1991) Oxidised LDL: a role in the pathogenesis of atherosclerosis in diabetes? Diabet Med 8: 411-419

13. Halliwell B (1996) Oxidative stress, nutrition and health: Experimental strategies for optimization of nutritional antioxidants intakes in humans. Free Rad Biol Med 25: 57-74

14. Velazques E, Winocour PH, Kesteven P, Alberti KGMM, Laker MF (1991) Relation of lipid peroxides to macrovascular disease in type 2 diabetes. Diabet Med 8: 752-758

15. MacRury SM, Gordon D, Wilson R et al. (1993) A comparison of different methods of assessing free radical activity in type 2 diabetes and peripheral vascular disease. Diabet Med 10: 331-335

16. Griesmacher A, KinderHauser M, Andert S et al. (1995) Enhanced serum levels of TBARS in diabetes mellitus. Am J Med 98: 469-475

17. Niskanen LK, Salonen JT, Nyssonen K, Uusitupa MIJ (1995) Plasma lipid peroxidation and hyperglycaemia: a connection through hyperinsulinaemia. Diabet Med 12: 802-808

18. Sundaram RK, Bhaskar A, Vijayalingam S, Viswanatthan M, Mohan R, Shanmugasundaram KR (1996) Antioxidant status and lipid peroxidation in type II diabetes with and without complications. Clin Sci 90: 255-260

19. Stringer MD, Gorog PG, Freeman A, Kakkar VV (1989) Lipid peroxides and atherosclerosis. BMJ 298: 281-284

20. Chirico S, Smith C, Marchant C, Mitchinson MJ, Halliwell B (1993) Lipid peroxidation in hyperlipidaemic patients. A study of plasma using an HPLC-based thiobarbituric acid test. Free Radical Res Comm 19: 51-57

21. Thompson KH, Godin DV (1995) Micronutrients and antioxidants in the progression of diabetes. Nutr Res 15: $1377-$ 1410

22. Tsai EC, Hirsch IB, Brunzell JD, Chait A (1994) Reduced plasma peroxyl radical trapping capacity and increased susceptibility of LDL to oxidation in poorly controlled IDDM. Diabetes 43: 1010-1014

23. Asayama K, Uchida N, Nakane Tet al. (1993) Antioxidants in the serum of children with IDDM. Free Radical Biol Med 15: 597-602

24. Nourooz-Zadeh J, Tajaddini-Sarmadi J, McCarthy S, Betteridge DJ, Wolff SP (1995) Elevated levels of authentic plasma hydroperoxides in NIDDM. Diabetes 44: 10541058

25. Volk GD, Nauta JJP, Strijers, Bertelsmann FW (1986) Clinical versus neurophysiological examination in the diagnosis of diabetic polyneuropathy. Diabet Med 9: 716-721

26. Gatling W, Knight C, Mullee MA, Hill RD (1988) Microalbuminuria in diabetes: a population study of the prevelance and an assessment of the three screening tests. Diabet Med 5: $343-347$ 
27. Menard L, Dempsey ME, Blankstein LA, Aleyassine H, Wacks M, Soeldner JS (1980) Quantitative determination of glycosylated hemoglobin $\mathrm{A}_{1}$ by agar gel electrophoresis. Clin Chem 26: 1598-1602

28. Nourooz-Zadeh J, Tajaddini-Sarmadi J, Wolff SP (1994) Measurement of plasma hydroperoxide concentrations by the ferrous-oxidation in xylenol (FOX) assay in conjunction with triphenylphosphine. Anal Biochem 220: 403-409

29. Gey KF (1986) On the antioxidant hypothesis with regard to arteriosclerosis. Bibl Nutr Dieta 37: 53-91

30. Thomas SM, Jessup W, Gebicki JM, Dean RT (1989) A continuous-flow automated assay for iodometric estimation of hydroperoxides. Anal Biochem 176: 353-359

31. Cramer GL, Miller JF, Pendleton RB, Lands WEM (1991) Measurement of lipid hydroperoxides in human plasma. Anal Biochem 193: 204-211

32. Marshall PJ, Warso MA, Land WEM (1985) Selective microdetermination of lipid hydroperoxides. Anal Biochem 145: 192-199

33. Zamburlini A, Maiorino M, Barbera P et al. (1995) Measurement of lipid hydroperoxides in plasma by a new highsensitive single photon counting luminometer. Biochem Biophys Acta 1256: 233-240

34. Zamburlini A, Maiorino M, Barbera P, Roveri A, Ursini F (1996) Direct measurement by single photon counting of lipid hydroperoxides in human plasma and lipoproteins. Anal Biochem 232: 107-113

35. Frei B, Yamamoto Y, Niclas D, Ames BN (1988) Evaluation of an isoluminol chemiluminescence assay for the detection of hydroperoxides in human blood plasma. Anal Biochem 175: 120-130

36. Miyazawa T (1989) Determination of phospholipid hydroperoxides in human blood plasma by a chemiluminescence-HPLC assay. Free Radical Biol Med 7: 209-217

37. Holley AE, Slater TR (1991) Measurement of lipid hydroperoxides in normal human blood plasma using HPLC-CL linked to a diode array detector for measuring conjugated dienes. Free Radical Res Commun 15: 51-63

38. Yamamoto Y, Brodsky MH, Baker JC, Ames BN (1987) Detection and characterisation of lipid hydroperoxides at picomole levels by HPLC. Anal Biochem 160: 7-13

39. Yamamotto Y, Niki E (1989) Presence of cholesteryl ester hydroperoxides in human blood plasma. Biochem Biophys Res Commun 165: 988-993

40. Coghlan JG, Flitter WD, Holley AE et al. (1991) Detection of free radicals and lipid hydroperoxides in blood taken from the coronary sinus of man during percutaneous transluminol coronary angioplasty. Free Radical Res Commun 14: 409-417
41. Jennings PE, Jones AF, Florkowski CM, Lunec J, Barnett AH (1987) Increased diene conjugates in diabetic subjects with microangiopathy. Diabet Med 4: 452-456

42. Gopaul NK, Anggard EE, Betteridge DJ, Wolff SP, Nourooz-Zadeh J (1995) Plasma 8-epi $\mathrm{PGF}_{2} \alpha$ levels are elevated in individuals with NIDDM. FEBS Lett 368: 225229

43. Yokota T, Tsuchiya K, Furukawa T, Tsukagoshi H, Miayakawa H, Hasumura Y (1990) Vitamin E deficiency in acquired fat malabsorption. J Neurol 237: 103-106

44. Martinoli L, Di-Felice M, Seghieri G et al. (1993) Plasma retinol and alpha-tocopherol concentrations in NIDDM. Int J Vitam Nutr Res. 63: 87-92

45. Singh RB, Ghosh S, Niaz MA et al. (1995) Dietary intake, plasma level of antioxidant vitamins, and oxidative stress in relation to coronary artery disease in eldery subjects. Am J Cardiol 76: 1233-1238

46. Reaven PD, Herold DA, Barnett J, Edelman S (1995) Effects of vitamin E on susceptibility of LDL and LDL subfractions to oxidation and on protein glycation in NIDDM. Diabetes Care 18: 807-816

47. Reaven P (1995) Dietary and pharmacologic regimens to reduce lipid peroxidation in NIDDM. Am J Clin Nutr 62[Suppl]:1483-1493

48. Haffner SM, Agil A, Mykkanen L, Stern M, Jialal I (1995) Plasma oxidisability in subjects with normal glucose tolerance, impaired glucose tolerance, and NIDDM. Diabetes Care 18: 646-653

49. Karpen CW, Cataland S, O'Dorisio TM, Panganamala RV (1985) Production of 12-HETES and vitamin E status in platelets from type I human diabetic subjects. Diabetes 34 : 526-531

50. Salonen JT, Nyyssonen K, Tuomainen TP et al. (1995) Increased risk of NIDDM at low vitamin E concentrations:a four year follow up study in men. BMJ 311: 1124-1127

51. Stampfer MJ, Hennekens CH, Manson JE, Coldtiz G, Rosener B, Willett WC (1993) Vitamin E consumption and the risk of coronary disease in women. New Engl J Med 328: $1444-1449$

52. Rimm EB, Stampfer MJ, Ascherio A, Giovannucci E, Colditz G, Willett WC (1993) Vitamin E consumption and the risk of coronary heart disease in men. New Engl J Med 328: $1450-1456$

53. Stephens NG, Parsons A, Schofield PM, Kelly F, Cheeseman K, Mitchinson J, Brown MJ (1996) Radomised controlled trial of vitamin $\mathrm{E}$ in patients with coronary disease: Cambridge heart antioxidant study (CHAOS). Lancet 347: 781-786 